\title{
Avaliação da Vulnerabilidade Social à ameaça de Fogo na Microrregião Tomé-Açu
}

\author{
Assessment of Social Vulnerability to the threat of fire in the Tomé-Açu Microregion \\ Evaluación de la vulnerabilidad social ante la amenaza de incendios en la microrregión de Tomé-
}

Açu

Recebido: 14/01/2022 | Revisado: 18/01/2022 | Aceito: 23/01/2022 | Publicado: 25/01/2022

\author{
Helena Joseane Raiol Souza \\ ORCID: https://orcid.org/0000-0001-9953-3752 \\ Universidade Federal do Pará, Brasil \\ E-mail: helena.joseane@gmail.com \\ Milena Marília Nogueira de Andrade \\ ORCID: https://orcid.org/0000-0001-5799-7321 \\ Universidade Federal Rural da Amazônia, Brasil \\ E-mail: milenamarilia.andrade@gmail.com
}

\begin{abstract}
Resumo
O fogo no Brasil tem apresentado recentemente números expressivos, atingindo fortemente a floresta tropical úmida, onde vários municípios do Pará lideram o número de queimadas e incêndios florestais, deixando consequências graves no bioma amazônico, elevando a vulnerabilidade dos habitantes das regiões mais afetadas. Logo, é necessário otimizar mecanismos de prevenção dos riscos e preparar comunidades para o enfrentamento a possíveis desastres, capacitando lideranças para tomada de decisões, elevando suas capacidades de resposta para a construção de comunidades resilientes. Este trabalho objetivou avaliar a vulnerabilidade social da Microrregião Tomé-açu (MRTA) à ameaça de fogo. Utilizou-se Sistemas de Informações Geográficas (SIG) e o ARCMAP 10.5 para elaboração dos mapas; para análises estatísticas multivariadas (K-Means clustering e PCA) usou-se o software R, versão 4.03. Fez-se a análise socioambiental considerando as variáveis demográficas (densidade demográfica e população rural), sociais (vulneráveis por faixa etária e grau de escolaridade) e ambientais (número de focos de calor, precipitação pluviométrica, uso do solo). Os principais resultados apontam o município de Concórdia do Pará com alta vulnerabilidade socioambiental à ameaça de fogo. Com média vulnerabilidade socioambiental aparece Acará, cujas varáveis ambientais favorecem a redução dessa vulnerabilidade, entretanto, as sociais contribuem negativamente para a construção desse indicador. Os demais municípios da MRTA (Moju, Tailândia e Tomé-açu) possuem parâmetros ambientais e sociais muito equivalentes e colaboraram para a construção do indicador de baixa vulnerabilidade socioambiental à ameaça de fogo. Essa pesquisa reforça a necessidade de elevar a escolaridade dessa população para o enfrentamento a possíveis desastres.
\end{abstract}

Palavras-chave: Capacidade de resposta; Criticidade; Resiliência.

\begin{abstract}
Recently, there have been many fires in Brazil, these strongly affecting the humid tropical forest. Several municipalities in Pará have had many fires and forest fires leaving serious consequences in the Amazon biome, increasing the vulnerability of the inhabitants of the most affected regions. Therefore, it is necessary to optimize risk prevention mechanisms and prepare communities to face possible disasters, training leaders for decision-making, raising their response capacities to build resilient communities. This study aimed to evaluate the social vulnerability of the Tomé-Açu Micro-region (MRTA) to the threat of fire. Geographic Information Systems (GIS) and ARCMAP 10.5 were used to prepare the maps; for multivariate statistical analyzes (K-Means clustering and PCA) R software, version 4.03 was used. A socio-environmental analysis was carried out considering demographic (demographic density and rural population), social (vulnerable by age group and level of education) and environmental variables (number of hotspots, rainfall, land use). The main results point to the municipality of Concórdia do Pará with high socioenvironmental vulnerability to the threat of fire. With medium socio-environmental vulnerability appears Acará, whose environmental variables favor the reduction of this vulnerability, however, the social ones contribute negatively to the construction of this indicator. The other municipalities in the MRTA (Moju, Tailândia and Toméaçu) have very similar environmental and social parameters and contributed to the construction of the indicator of low socio-environmental vulnerability to the threat of fire. This research reinforces the need to increase the education of this population to face possible disasters.
\end{abstract}

Keywords: Responsiveness; Criticality; Resilience. 


\begin{abstract}
Resumen
El fuego en Brasil presenta recientemente números expresivos, afectando fuertemente el bosque tropical húmedo, donde varios municipios de Pará lideran el número de quemas e incendios forestales, dejando graves consecuencias en el bioma amazónico, aumentando la vulnerabilidad de los habitantes de las regiones más afectadas. Ahora, es necesario optimizar mecanismos de prevención de riesgos y preparar la comunidad para enfrentar posibles desastres, capacitando lideres para la toma de decisiones, aumentando sus capacidades de respuesta para construir comunidades resilientes. Este trabajo tuvo como objectivo valorar la vulnerabilidad social de la Microrregión Tomé-Açú (MRTA) a la amenaza de fuego. Fueron usados Sistemas de Información Geográficas (SIG) y el ARCMAP 10.5 para la elaboración de los mapas; para los análisis estadísticos multivariables (K-Means Clustering e PCA) se usó el software $\mathrm{R}$ versión 4.03. Se realizó un análisis socioambiental con base en las variables demográficas (densidad demográfica y población rural), sociales (vulnerables por grupo de edad y nivel educativo) y ambientales (número de fuentes de calor, precipitaciones, uso de suelo). Los principales resultados señalan que el municipio de Concórdia de Pará tiene una alta vulnerabilidad socioambiental a la amenaza de fuego. Con media vulnerabilidad socioambiental para Acará, cuyas variables ambientales favorecen la reducción de esa vulnerabilidad, sin embargo, las sociales contribuyen negativamente a la construcción de este indicador. Los demás municipios del MRTA (Moju, Tailândia y Tomé-Açu) tienen parámetros ambientales y sociales equivalentes y colaboran para la construcción del indicador de baja vulnerabilidad socioambiental a la amenaza de fuego. Esta investigación refuerza la necesidad de incrementar la educación de esa población para enfrentar posibles desastres.
\end{abstract}

Palabras clave: Sensibilidad; Criticidad; Resiliencia.

\title{
1. Introdução
}

O fogo, muitas vezes, encontra-se associado a destruição e catástrofes, no entanto, foi uma das primeiras grandes descobertas revolucionárias da humanidade a alguns milhões de anos atrás, mais precisamente, no paleolítico inferior (Hirst, 2019, Musitano, 2019). Pesquisas revelam que as primeiras evidências do uso do fogo por humanos foram encontradas em sítios de hominídeos no Quênia. Estes utilizavam o fogo para cozinhar, produzir luz e calor, prevenir-se contra animais predadores, limpar florestas para plantar, produzir objetos de cerâmicas por meio de argila queimada, produzir ferramentas de pedra e, a partir dessa descoberta, o homem rumou a caminho da civilização com a modificação do ambiente ao seu redor para suas atividades (Hirst, 2019).

Apesar do fogo estar ligado às mudanças do uso e cobertura da terra desde sua descoberta, nos últimos anos, a mídia registrou incêndios florestais de grande magnitude, consequência, dentre outros fatores, de estiagens severas, deixando muitas vítimas fatais e danos à biodiversidade local. Destes, destacam-se os ocorridos na Grécia em 2018, Portugal (2003 e 2017), Victoria (Austrália), em 2009, Roraima (1997-1998), Paragominas-Pará (1998) e tantos outros não menos intensos ou severos (Cochrane, 2000, AFP, 2018; Anderson et al., 2019). Dados do Instituto Nacional de Pesquisas Espaciais (INPE) mostram que durante o período de 2010 a 2019, no Brasil, o número total de focos de calor identificados foi de 348.646, onde cerca de $43 \%$ ocorreram na Amazônia, o que corresponde a aproximadamente 22\% do total de área queimada no Brasil (INPE, 2020).

Sustentando que existem efeitos benéficos produzidos pelo fogo, surgem as "queimadas controladas", usadas para limpeza de áreas que, geralmente, ocorre após desmatamento (SEMAS, 2010; Costa et al., 2011). Ao sair do controle, essas queimadas transformam-se em incêndios florestais causando enormes prejuízos à sociedade e aos ecossistemas (Santos et al., 2020). As causas que originam esse tipo de evento são classificadas em estruturais (fatores ambientais e sociais), e determinantes (fatores naturais e antrópicos). Os parâmetros para avaliar o comportamento desses incêndios adotam as características da vegetação (combustível) e do relevo associados a elementos e fatores climáticos, tais como radiação solar, umidade do ar, temperatura, precipitação, altitude, latitude e massas de ar (Xiong et al., 2020).

A quase totalidade das ocorrências de fogo descontrolado (queimadas e incêndios florestais) está associada a causas estruturais e ou determinantes, entretanto, não se pode desconsiderar a influência de fenômenos atmosféricos-oceânicos como El Niño Oscilação (ENOS) que afeta o globo terrestre como um todo e, em particular, causam o aparecimento de grandes períodos de seca severa na região Norte do Brasil, causando sérios transtornos socioeconômicos (Sousa et al., 2015). 
Na Amazônia, o fogo sempre foi utilizado tradicionalmente para diversos fins, pois famílias de pequenos agricultores, extrativistas, ribeirinhos, indígenas, pescadores ainda o utilizam em grande escala, por ser o fogo uma ferramenta importante e de baixo custo em atividades como renovação do solo, formação de pastos, extrativismo, dentre outras (Marinho et al., 2021). A intervenção do homem no processo de queima, precipitações reduzidas somadas à elevação da temperatura de $2^{\circ}$ a $8^{\circ} \mathrm{C}$ até o fim do século, estão contribuindo com o aumento da inflamabilidade do bioma amazônico, o que poderá gerar um possível processo de "savanização" da floresta (Fonseca-Morello et al., 2017). Já investimentos em edificações seguras, pastagens apropriadas, reflorestamento, culturas perenes, sistemas agroflorestais funcionam como incentivo em prevenção e controle desestimulando o uso do fogo. (Nepstad et al., 1999).

Embora já existam sistemas de vigilância das florestas com emprego de imagens de satélites e órgãos como IBAMA (Instituto Brasileiro do Meio Ambiente e dos Recursos Naturais Renováveis), INPE (Instituto Nacional de Pesquisas Espaciais) e outros em âmbitos federal, estadual e municipal, atuando no monitoramento e prevenção de focos de incêndios, estes eventos ainda são um sério problema, pois ainda se observa um incipiente manejo ambiental diante da larga expansão da agricultura e da bovinocultura em imensas áreas no país (Bacani, 2016; Anderson et al., 2019; Souza et al., 2021). Políticas públicas e pesquisas científicas voltadas para a questão da prevenção e controle de incêndios florestais ainda estão muito aquém do ideal, já que estudos recentes apontem para a questão do aumento de incidência de desastres associados a incêndios florestais no Brasil (Anderson et al., 2019, Anderson \& Marchezini, 2020). Conhecer os fatores que desencadeiam os desmatamentos e as queimadas e influenciam nos incêndios florestais é necessário para direcionar Políticas Públicas nas tomadas de decisão (Fonseca-Morello et al., 2017).

Após cem anos de colonização do Nordeste paraense, ainda é muito frequente a agricultura de corte-e-queima (Rebello \& Homma, 2017). Esta região sofreu imensa antropização em seus sistemas e subsistemas produtivos havendo uma extensa mudança de uso e cobertura da terra. Áreas anteriormente cobertas por florestas com rica biodiversidade foram substituídas por pastagens degradadas e vegetação em diferentes etapas sucessionais, resultado de atividades madeireiras, ampliação de produção agropecuária, agricultura local sem incentivo, caça predatória e uso indiscriminado de fogo ao preparar a terra (Cordeiro et al., 2017).

Estudos de análise multitemporal de focos de queimada desenvolvidos no Pará apontam que as mesorregiões Sudeste, Sudoeste e Nordeste paraense apresentaram o maior número de focos de calor, já que estas regiões possuem atividades econômicas voltadas para a pecuária e agricultura em larga escala, com limpeza das áreas e consequente eliminação de resto de culturas, gerando, por vezes, queimadas ilegais ultrapassando as fronteiras das propriedades rurais (Santos et al., 2020). A mesorregião Nordeste paraense, uma das seis do Estado do Pará, destaca-se por ser a mais antiga em termos de colonização na Amazônia, possui 49 municípios, e 24,13\% dos habitantes do estado distribuídas em cinco microrregiões (Bragantina, Cametá, Guamá, Salgado e Tomé-açu) (IBGE, 2010).

A microrregião de Tomé-açu apesar do baixo Índice de Desenvolvimento Humano (IDH), apresenta um grande potencial edafoclimático, levando o governo do Estado a criar políticas de incentivo a grupos nacionais e internacionais para implantação da monocultura do dendê (Elaeis guineenses Jacq.) (Nahum et al., 2012). Esta monocultura usa o fogo no processo de implantação e expõe uma maior quantidade de pessoas aos riscos do fogo, tornando-as socioambientalmente vulneráveis aos seus efeitos, influenciando a saúde e qualidade de vida dessa população (Gonçalves et al., 2014).

Nesse cenário e de forma a prevenir o surgimento de queimadas ou incêndios florestais, realiza-se no estado do Pará, o monitoramento hidrometeorológico, através da Secretaria de Estado de Meio Ambiente e Sustentabilidade (SEMAS), que emite os resultados em formato de boletins, com informações de focos de calor observados nos municípios, bem como as condições meteorológicas favoráveis, ou não, ao surgimento de incêndios florestais, com risco de suscetibilidade ao fogo e previsão de incêndios florestais baseado nas condições meteorológicas (SEMAS, 2010). 
Tais ações são relevantes pois identificam a relação entre áreas com alta probabilidade de incêndios florestais e alta vulnerabilidade social para uma melhor gestão do risco (Wigtil et al., 2016), uma vez que, as principais consequências da exposição do material particulado no pós-queima evidenciam efeitos na saúde de crianças e idosos com o aumento de doenças respiratórias (Castro et al., 2009).

Nesse contexto, a vulnerabilidade pode ser definida como processos sociais ligados à fragilidade da proteção social e à precariedade das condições de vida (educação, saneamento, renda, saúde etc.), aliados aos impactos resultantes da degradação do ambiente, tornando mais vulneráveis certos grupos populacionais (mulheres, idosos e crianças) e determinadas áreas (Freitas et al., 2012). Assim, o objetivo deste trabalho foi analisar a vulnerabilidade socioambiental da população da microrregião de Tomé-açu frente aos perigos derivados do fogo.

\section{Metodologia}

A metodologia deste trabalho contou com as seguintes etapas metodológicas: pesquisa bibliográfica, levantamento e análise de dados secundários obtidos de plataformas abertas, utilização de Sistemas de Informações Geográficas (SIG), construção de mapas no software ARCGIS 10.5, análises multivariadas (K-Means clustering e Análise da Componente Principal) no software R.

\section{1 Área de estudo}

A Microrregião Tomé-açu (MRTA) está localizada no Nordeste do Estado do Pará, possui uma área de $23.802 \mathrm{~km}^{2}$, situa-se entre Latitude $2^{\circ} 54^{\prime} 45^{\prime \prime}$ e $3^{\circ} 16$ 36' Sul e Longitude $47^{\circ} 55^{\prime} 38^{\prime \prime}$ e $48^{\circ} 26^{\prime} 44^{\prime \prime}$ Oeste, é composta por cinco municípios: Acará, Concórdia do Pará, Moju, Tailândia e Tomé-açu (Figura 1) e possui população estimada em torno de 341 mil habitantes (IBGE, 2019). As principais vias de acesso são as rodovias estaduais PA-140, PA-150, PA-252 e PA- 256 (DNIT, 2019).

A rede hidrográfica da MRTA é constituída, principalmente, pelos rios Acará, Guamá e Moju e seus subafluentes (ANA, 2020). A climatologia regional apresenta valores de Precipitação Média Anual (PMA) variando entre 1.750 mm e 3.000 mm correspondendo ao período de meses menos chuvosos e mais chuvosos, respectivamente, e está classificada climaticamente como Af, segundo a classificação de Köppen (Alvares et al., 2013). As temperaturas anuais possuem baixa amplitude entre $24^{\circ} \mathrm{C}$ a $27^{\circ} \mathrm{C}$ (Santos et al., 2019). 
Figura 1: Mapa de localização da Microrregião de Tomé-açu.

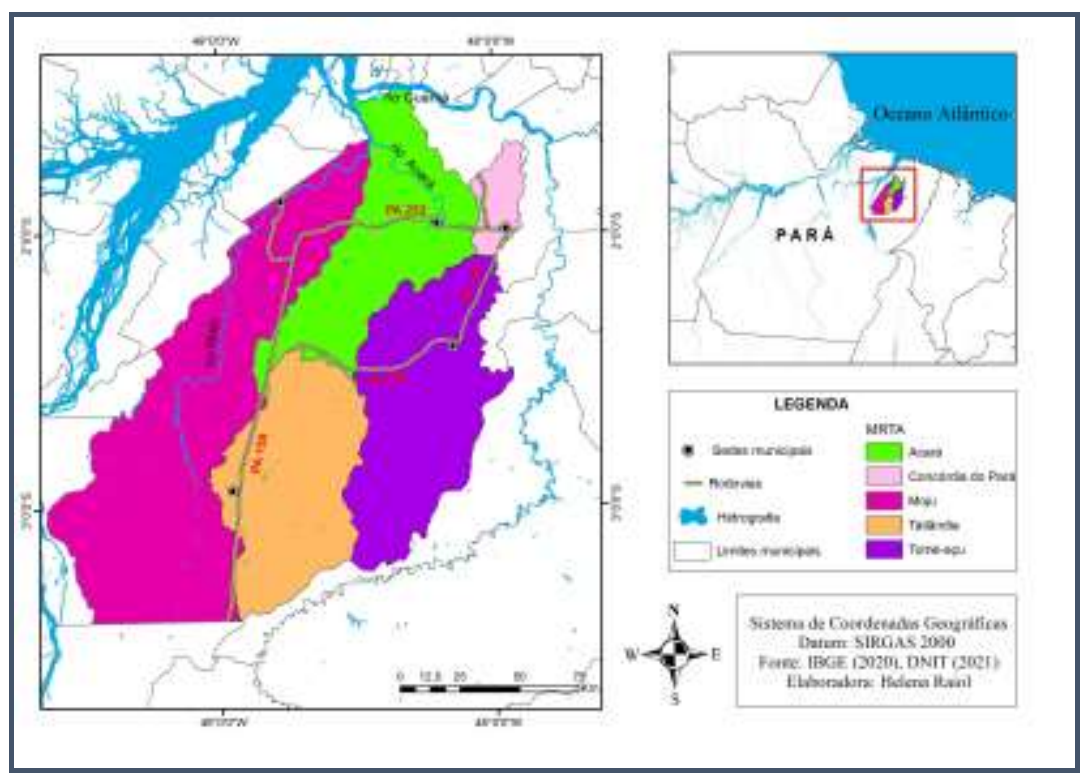

Fonte: Autores.

\subsection{Aspectos da vegetação}

A fisiografia local é representada por floresta fechada e densa com árvores de grande porte adaptadas, que suportam elevada quantidade de água (higrófitas), com presença de matas de terra firme, várzea e igapó (Santos et al., 2019).

As classes do uso e cobertura da terra para a área de estudo estão divididas em $45 \%$ de floresta primária, 3,70\% de floresta secundária, $16 \%$ de pastagem, $1 \%$ de área usada para agricultura e o restante refere-se a plantas em etapas de sucessão em fase inicial, reflorestamentos e áreas não observadas, consequência do processo de antropização e desmatamento (Cordeiro et al., 2017).

A vegetação original da MRTA era composta totalmente por floresta ombrófila densa, minimamente alterada, com espécies botânicas de elevado valor comercial, muitas delas, atualmente, em situação de vulnerabilidade, como é o caso do mogno, castanheira, angelim e cerejeira (Santos et al., 2019). A cobertura vegetal dessa floresta foi suprimida ao longo dos anos devido a variados usos, e foi incorporada de maneira inadequada à produção agropastoril, expansão da malha urbana, dentre outros, sendo convertida, progressivamente, em floresta secundária (capoeira) ou solo exposto, após o uso temporário e indevido da terra (exploração madeireira, pastagem, agricultura e o agronegócio) (Araújo et al., 2011).

Atualmente essa cobertura vegetal se apresenta da seguinte forma: floresta $(60,9 \%)$, pastagem $(18,4 \%)$ e dendezais (9,6\%) (Santos et al., 2019). Após a derrubada das matas para a construção de rodovias, já era possível observar as primeiras alterações na paisagem, alterando a fisiogeografia local, ocasionadas por intervenção antrópica em que essas matas naturais foram substituídas por fazendas de criação de bovinos que, juntas com lavouras de subsistência, suscitaram os núcleos urbanos da MRTA (Cardoso et al., 2008).

\subsection{Aspectos étnicos da população}

Essa microrregião tem como principais representantes étnicos os remanescentes quilombolas e indígenas (representantes da população tradicional), os portugueses e forte presença de nordestinos, que chegaram à região durante um fluxo migratório muito intenso em meados da década de 70. Em Moju, ainda é possível encontrar um grupo indígena e em Tomé-açu, quatro grupos (INCRA, 2019). Ainda entre os anos 50 e 80, os militares promoveram o programa "Integração Nacional", quando ocorreu um novo ciclo de ocupação, em virtude da construção de grandes rodovias como a BR-010, BR- 
316 e BR-222 (Cordeiro et al., 2017). Outro período de destaque da colonização foi em 1929 com a imigração japonesa por meio de um acordo entre os governos brasileiro e japonês, solucionando dois problemas: a ocupação da Amazônia com mãode-obra capaz de povoar a região e a emigração de camponeses que viviam em situação difícil no Japão (Carvalho, 2016).

Estes ciclos de ocupação e desenvolvimento acarretaram mudanças na paisagem, refletindo em valores culturais, socioeconômicos, ambientais e políticos dos novos habitantes, culminando com a expulsão de populações tradicionais dos seus locais de origem. Esses aspectos peculiares não estão embasados somente no modo de colonização, mas, sobretudo, nos processos diferenciados das relações dos imigrantes com o meio ambiente (Cordeiro et al., 2017).

\subsection{Aspectos das atividades econômicas}

Esta mesorregião merece destaque por apresentar as seguintes frentes de produção: farinha de mandioca, o extrativismo e a produção de gêneros alimentícios tipicamente amazônicos (açaí, castanha-do-Pará, palmito), e a produção de dendê destinada tanto para a indústria alimentícia quanto para a de biocombustíveis (Pinho, 2015).

Esta microrregião oferece condições edafoclimáticas propícias para a cultura do dendê que, aliada a condição da população predominantemente rural dos municípios desta microrregião, cujos Índices de Desenvolvimento Humano (IDH) são baixos: Acará (0,506), Concórdia do Pará (0,566), Moju (0,547), Tailândia $(0,588)$ e Tomé-açu $(0,586)$, e muitas famílias beneficiadas por programas do governo Federal. Desse modo, o governo do Estado criou políticas de incentivo a grupos nacionais e internacionais de implantação da dendeicultura na região (IBGE, 2010, Nahum et al., 2012), aliando as condições climáticas favoráveis à implantação da monocultura do dendê à condição da população predominantemente rural dessa microrregião.

Nesse contexto, a localização preferida dos investidores para o plantio do dendê são os municípios de Moju, Tailândia, Acará e Tomé-açu, onde se concentram as maiores áreas e as três empresas de mais destaque no ramo (Agropalma, Biopalma e BBB/Petrobras/Galp) que, além de possuir propriedades próprias, também constituem parceria com agricultores camponeses da região (Lameira et al., 2015).

\subsection{Indicador de vulnerabilidade socioambiental}

O Indicador Socioambiental integra variáveis pertencentes a dimensões demográfica, social e ambiental (Figura 2). 
Figura 2: Fluxograma da obtenção dos escores e das classificações de vulnerabilidade para as dimensões demográfica, social, ambiental e socioambiental.

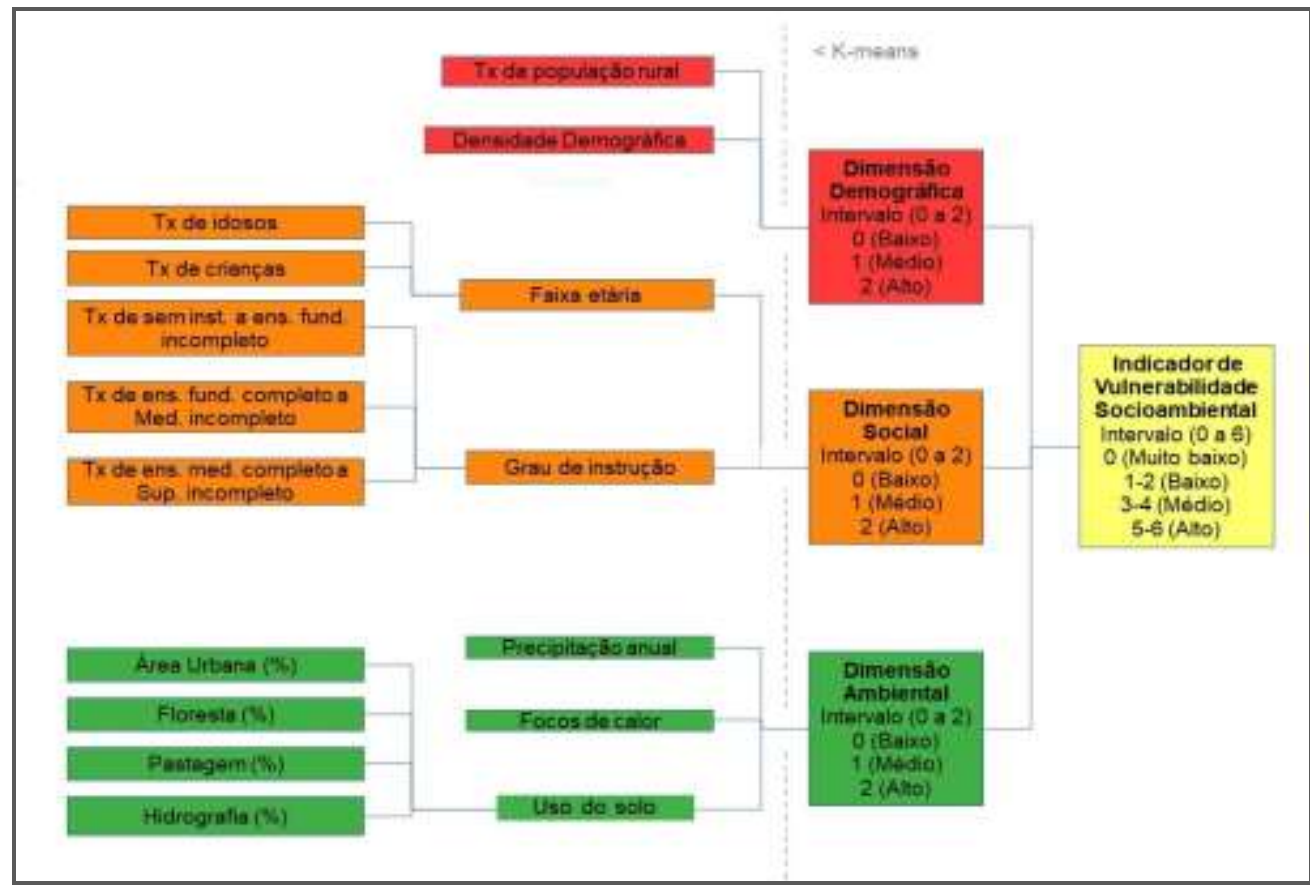

Fonte: Autores, adaptado de Morato (2008).

\subsubsection{Obtenção das dimensões sociais e ambientais}

As variáveis foram escolhidas de acordo com sua influência na vulnerabilidade socioambiental justificadas de acordo com a literatura e calculadas a partir de métodos específicos (Quadro 1).

Quadro 1 - Fatores escolhidos para a construção dos indicadores de vulnerabilidade.

\begin{tabular}{|c|c|c|c|c|c|}
\hline Dimensão & Indicador & Variáveis & Justificativa & Fonte & Fórmula/Método \\
\hline Social & Faixa etária & Crianças e idosos & $\begin{array}{l}\text { Crianças e idosos possuem } \\
\text { reduzida mobilidade e dependem } \\
\text { de outras pessoas para agir, } \\
\text { locomover e } \\
\text { idoson possui saúde frágil, o que } \\
\text { potencializa sua condição } \\
\text { vulnerável (Mitchell et al., 2009; } \\
\text { Bodstein et al., 2014) }\end{array}$ & IBGE (2010) & $\begin{array}{l}\qquad T x_{C}=\frac{C}{P_{T}} \\
\qquad T x_{I}=\frac{I}{P_{T}} \\
T x_{C I}=T x_{C}+T x_{I} \\
T x_{C}=\text { Taxa de Crianças } \\
T x_{I}=\text { Taxa de Idosos } \\
T x_{C I}=\text { Taxa de Crianças e Idosos } \\
\text { C = Número total de crianças } \\
\text { I = Número total de idosos } \\
P T=\text { Pop. total do município }\end{array}$ \\
\hline
\end{tabular}




\begin{tabular}{|c|c|c|c|c|c|}
\hline & $\begin{array}{l}\text { Grau de } \\
\text { Instrução }\end{array}$ & $\begin{array}{l}\text { Sem escolaridade, } \\
\text { fundamental } \\
\text { incompleto, } \\
\text { fundamental completo, } \\
\text { médio completo, médio } \\
\text { incompleto, superior } \\
\text { incompleto }\end{array}$ & $\begin{array}{l}\text { Quanto maior o grau de } \\
\text { escolaridade maior } \\
\text { conhecimento sobre os riscos a } \\
\text { que a população está exposta } \\
\text { (Gamba \& Ribeiro, 2012) }\end{array}$ & IBGE (2010) & $\begin{array}{l}\qquad T x_{G E}=\frac{P_{G E}}{P_{T}} \\
T x_{G E}=\text { Taxa de pessoas por Grau de } \\
\text { Escolaridade } \\
P_{G E}=\text { Número de pessoas por Grau } \\
\text { de Escolaridade } \\
P_{T}=\text { Pop. total do município. }\end{array}$ \\
\hline & $\begin{array}{l}\text { Densidade } \\
\text { demográfica }\end{array}$ & População rural & $\begin{array}{l}\text { Pessoas que habitam em zonas } \\
\text { rurais estão mais vulneráveis } \\
\text { porque estão mais próximas da } \\
\text { vegetação susceptível ao fogo e } \\
\text { mais atreladas às atividades que } \\
\text { o usam para diversos fins. } \\
\text { (Nepstad et al., 1999) }\end{array}$ & IBGE (2010) & $\begin{array}{l}\qquad T x_{P R}=\frac{P_{R}}{P_{T}} \\
T x_{\mathrm{PR}}=\text { Taxa de População Rural por } \\
\text { município. } \\
P_{\mathrm{PR}}=\text { População Rural } \\
P_{T}=\text { População total do município }\end{array}$ \\
\hline \multirow[t]{3}{*}{ Ambiental } & $\begin{array}{l}\text { Precipitação } \\
\text { anual }\end{array}$ & $\begin{array}{l}\text { Volume de precipitação } \\
\text { pluviométrica }\end{array}$ & $\begin{array}{l}\text { A quantidade de chuvas em } \\
\text { determinada área, aliada a outros } \\
\text { elementos e fatores climáticos, } \\
\text { contribui, sobremaneira, para o } \\
\text { surgimento de focos de calor. }\end{array}$ & $\begin{array}{l}\text { ANA (2020) } \\
\text { GPCC (2020) }\end{array}$ & $\begin{array}{c}\bar{X}=\frac{\sum_{n=11}^{n=1 \Sigma} X}{12} \\
\bar{X}=\text { Média de Precipitação mensal } \\
\qquad \bar{P}=\frac{\sum_{n=\Perp 1}^{n=}}{10} \\
\bar{P}=\sum \text { precipitação anual } / 10 \\
\text { Análise histórica } 2010-2019\end{array}$ \\
\hline & $\begin{array}{l}\text { Focos de } \\
\text { Calor }\end{array}$ & $\begin{array}{l}\text { Quantidade e densidade } \\
\text { de focos de calor }\end{array}$ & $\begin{array}{l}\text { A presença de focos de calor é } \\
\text { uma ameaça no período mais } \\
\text { seco, quando as comunidades } \\
\text { rurais o utilizam para fins } \\
\text { diversos. }\end{array}$ & $\begin{array}{l}\text { INPE (2020), } \\
\text { ARCGIS 10.5 }\end{array}$ & $\begin{array}{l}\qquad \begin{array}{l}\text { F= } \sum_{n=1}^{n=12} F \\
\text { F = total de focos de calor anual }\end{array} \\
\text { Densidade de Kernel (análise } \\
\text { histórica 2010-2019) }\end{array}$ \\
\hline & Uso do solo & $\begin{array}{l}\text { Presença } \text { de } \\
\text { primárias, } \\
\text { e } \text { em }\end{array}$ & $\begin{array}{l}\text { A observação de classes } \\
\text { referentes às áreas e suas } \\
\text { coberturas vegetais indicam as } \\
\text { possíveis atividades ocorrentes e } \\
\text { apontam regiões mais } \\
\text { susceptíveis à ameaça de fogo. }\end{array}$ & $\begin{array}{l}\text { ARCGIS 10.5, } \\
\text { ENVI versão } \\
5.0\end{array}$ & $\begin{array}{l}T x_{c}=\frac{A c}{A} * 100 \\
T x_{c}=\text { Taxa de classe, } \\
\text { Ac }=\text { Área de cada classe }\left(\mathrm{Km}^{2}\right), \\
\text { A }=\text { Área total do município }\left(\mathrm{Km}^{2}\right) \\
\text { em } 2019 .\end{array}$ \\
\hline
\end{tabular}

Fonte: Autores.

\subsection{Cálculos dos escores de vulnerabilidade}

Para o cálculo dos escores de Indicadores demográfico, social e ambiental dos municípios organizou-se as variáveis, previamente definidas, em ordem crescente, definindo-se para o maior valor $\left(V_{\max }\right)$ o número um e para o menor valor $\left(V_{\min }\right)$ o número zero. Os valores intermediários foram calculados a partir das equações abaixo (Morato, 2008).

$$
V_{1}=\frac{\left(V_{o b s}-V_{\min }\right)}{\left(V_{\max }-V_{\min }\right)} \quad V_{2}=\frac{\left(V_{\max }-V_{o b s}\right)}{\left(V_{\max }-V_{\min }\right)}
$$


Onde:

$\mathrm{V}_{1}=$ Valor intermediário para variáveis diretamente proporcionais a risco ambiental

$\mathrm{V}_{2}=$ Valor intermediário para variáveis inversamente proporcionais a risco ambiental

$\mathrm{V}_{\mathrm{obs}}=$ Valor observado

$\mathrm{V}_{\min }=$ Valor mínimo

$\mathrm{V}_{\max }=$ Valor máximo

\subsection{Classificação de vulnerabilidade demográfica, social, ambiental e socioambiental}

Os mapas temáticos da MRTA foram elaborados no software ArcGIS 10.5 utilizando o datum SIRGAS 2000 UTM 22S, escala 1:1.250.000, usando-se dados vetoriais de divisão administrativa da MRTA disponibilizados pelo IBGE. Para cada variável socioambiental foi atribuído um escore a partir da análise k-means referente a classificação final da vulnerabilidade, as cores foram atribuídas de acordo com os escores encontrados, de forma a categorizar as vulnerabilidades demográfica, social, ambiental e socioambiental (Quadro 2), esta última é a soma dos escores das demais vulnerabilidades.

Quadro 2 - Atribuição de cores para as classificações das vulnerabilidades demográfica, social e ambiental.

\begin{tabular}{|c|c|c|}
\hline Escore & Cor & Classificação \\
\hline 0 & Branco & Muito baixa \\
\hline $1-2$ & Verde & Baixa \\
\hline $3-4$ & Amarelo & Média \\
\hline $5-6$ & Vermelho & Alta \\
\hline
\end{tabular}

Fonte: Autores.

Para a confecção dos mapas de focos de calor utilizou-se o software ARCMAP versão 10.5 e dados de localização da MRTA em formato shapefile (IBGE, 2019). Os dados de focos de calor, também em shapefile, foram obtidos do banco de Queimadas do Instituto Nacional de Pesquisas Espaciais (INPE). O sistema de coordenadas geográficas adotado foi o SIRGAS 2000 UTM 22S. Seguiu-se a classificação de cores (Quadro 3) de acordo com os valores encontrados pela ferramenta de estimativa de densidade de Kernel, variando de acordo com a presença de focos de calor detectados. Essa ferramenta está disponível no menu arctoolbox "Spatial Analist tools”, “Kernel Density” e aplica uma função matemática 1(um), na posição do ponto a 0 (zero), na fronteira da vizinhança, criando uma delimitação circular ao redor de cada ponto da amostra a partir do seu raio de influência com o intuito de identificar os pontos de maior concentração (Silverman, 1986).

Quadro 3 - Atribuição de cores para as classificações das vulnerabilidades segundo as densidades de focos de calor.

\begin{tabular}{|c|c|}
\hline Cor & Classificação \\
\hline Branca & Muito baixa \\
\hline Verde & Baixa \\
\hline Amarela & Média \\
\hline Laranja & Alta \\
\hline Vermelha & Muito Alta \\
\hline
\end{tabular}

Fonte: Autores. 


\section{Resultados e Discussão}

\subsection{Vulnerabilidade sociodemográfica}

Na MRTA, em dez anos, houve o aumento da população com consequente concentração de pessoas nas áreas urbanas, inferindo-se que Tailândia, Tomé-açu e Concórdia do Pará possuem mais pessoas residindo na área urbana (Gráfico 1). O município de Tailândia se destaca pois possui população de aproximadamente 60 mil pessoas, pouco mais que o dobro da população residente na área rural. No município de Acará, a população rural se aproxima de 41 mil pessoas, três vezes e meio a mais que a urbana e em Moju predomina a população residente na área rural (cerca de 29 mil).

Gráfico 1- Número de habitantes nas zonas rural e urbana dos municípios da MRTA.

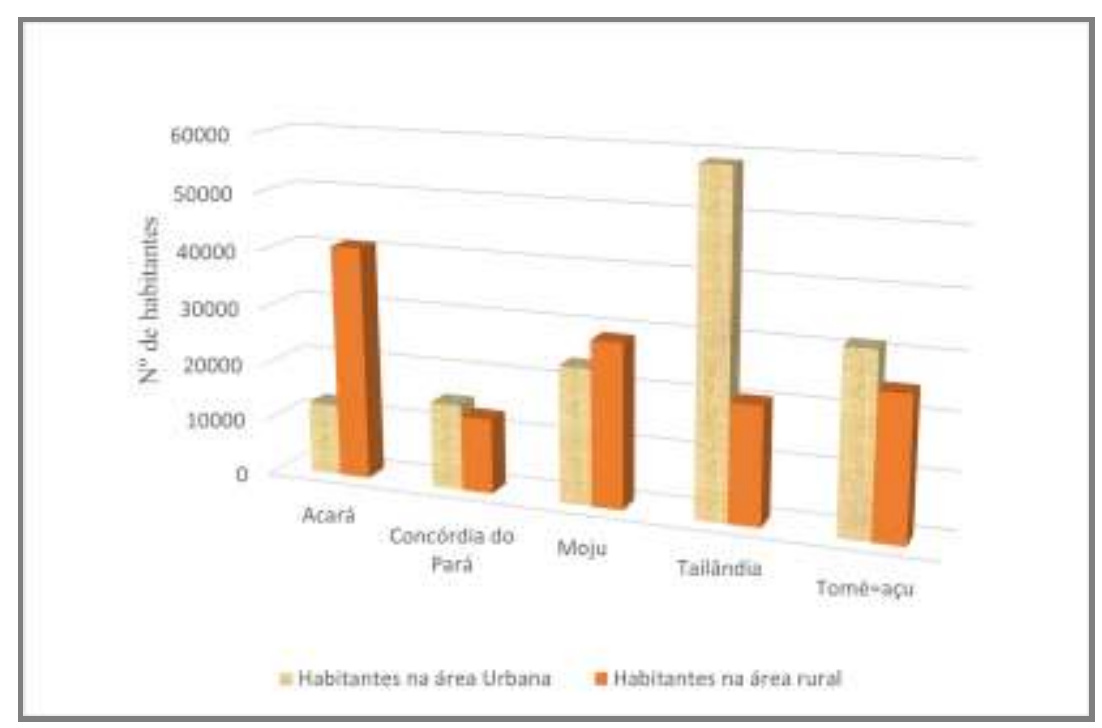

Fonte: Autores. Dados IBGE (2010).

No período estudado observou-se o aumento populacional dos municípios da MRTA o que gerou aumento na densidade demográfica. Acará passou de 12,33hab. $/ \mathrm{km}^{2}$ para 12,80hab. $/ \mathrm{km}^{2}$, Concórdia do Pará, de 40,84 hab./km² para 47,56

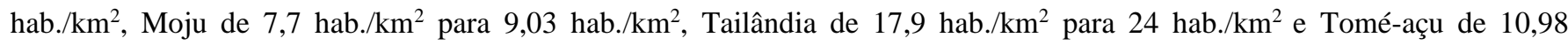
hab. $/ \mathrm{km}^{2}$ para 12,33 hab./km². Nota-se que, entre 2010 e 2019, os municípios sofreram acréscimo em sua população: Tailândia em 25,43\%, seguido por Concórdia do Pará (15,31\%), Moju (14,71\%), Tomé-açu (12,91\%) e Acará $(3,64 \%)$.

A distribuição da densidade populacional rural, com base na distribuição dos setores censitários, referente ao ano de 2019 da área de estudo pode ser melhor observada espacialmente na porção norte dos municípios de Moju, Acará e Concórdia do Pará (Figura 3). Moju representa 38,36\% da MRTA, portanto, é o maior município em área territorial dessa microrregião, apresenta densidade demográfica relativamente baixa $\left(9,03 \mathrm{hab} . / \mathrm{Km}^{2}\right)$ e pouco mais da metade da população residindo em área rural, com distribuição de pessoas variando entre zero a dez/ $\mathrm{Km}^{2}$, concentradas ao norte do município. Acará sofreu pouca variação tanto no aumento populacional como em sua densidade demográfica e apresenta apenas $24 \%$ de sua população residindo em área urbana, com adensamento populacional mais expressivo ocupando aproximadamente a porção norte e central do município. Concórdia do Pará, detentor da maior densidade demográfica acomoda sua população em um território que representa 2,9\% de toda a MRTA e adensamentos populacionais relativamente bem distribuídos na porção norte e central do município. 
Tomé-açu, que possui densidade demográfica relativamente baixa e a maior concentração populacional em áreas urbanas, com número de pessoas variando de zero a dez habitantes / $\mathrm{Km}^{2}$ na maior parte do município. Tailândia, apesar de exibir densidade demográfica elevada comparando-se aos demais municípios da microrregião, possui adensamento populacional variando de zero a dez habitantes/ $\mathrm{Km}^{2}$ em sua zona rural.

Figura 3 - Adensamento populacional nas zonas rurais dos municípios da MRTA.

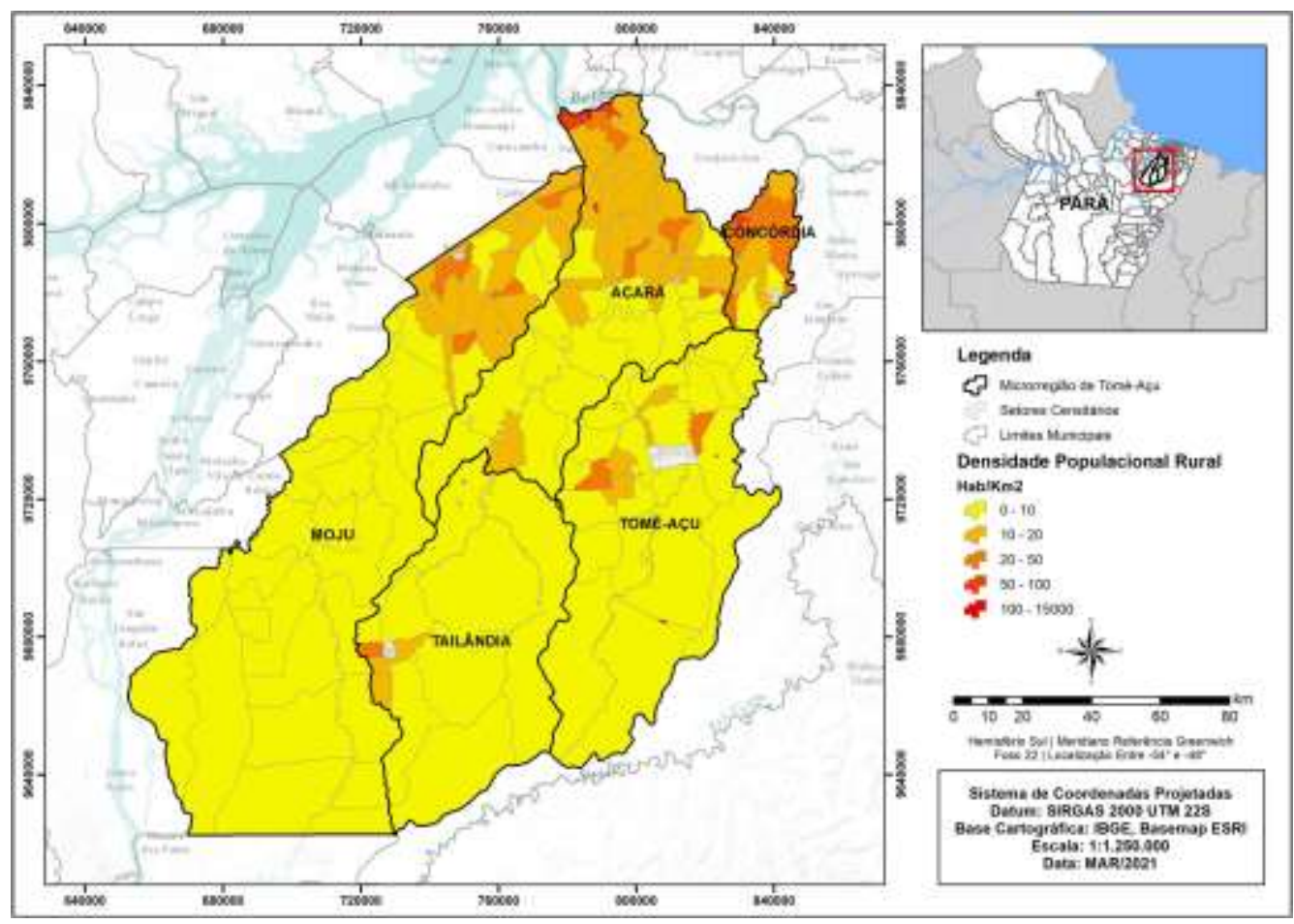

Fonte: Autores. Dados: IBGE (2010).

Na classificação de vulnerabilidade demográfica (Figura 4), o município de Concórdia do Pará foi classificado sob alta vulnerabilidade demográfica apesar de ter a menor área territorial da MRTA, pois $47 \%$ de sua população reside na zona rural. Acará está sob média vulnerabilidade demográfica pois sofreu pouco incremento populacional e em sua densidade demográfica, entretanto, apresenta cerca de $76 \%$ de sua população residindo em área rural e densidade demográfica de 12,80 hab./Km². Tailândia, Moju e Tomé-açu foram classificados como baixa vulnerabilidade demográfica à ameaça do fogo. 
Figura 4 - Classificação de vulnerabilidade demográfica para a MRTA.

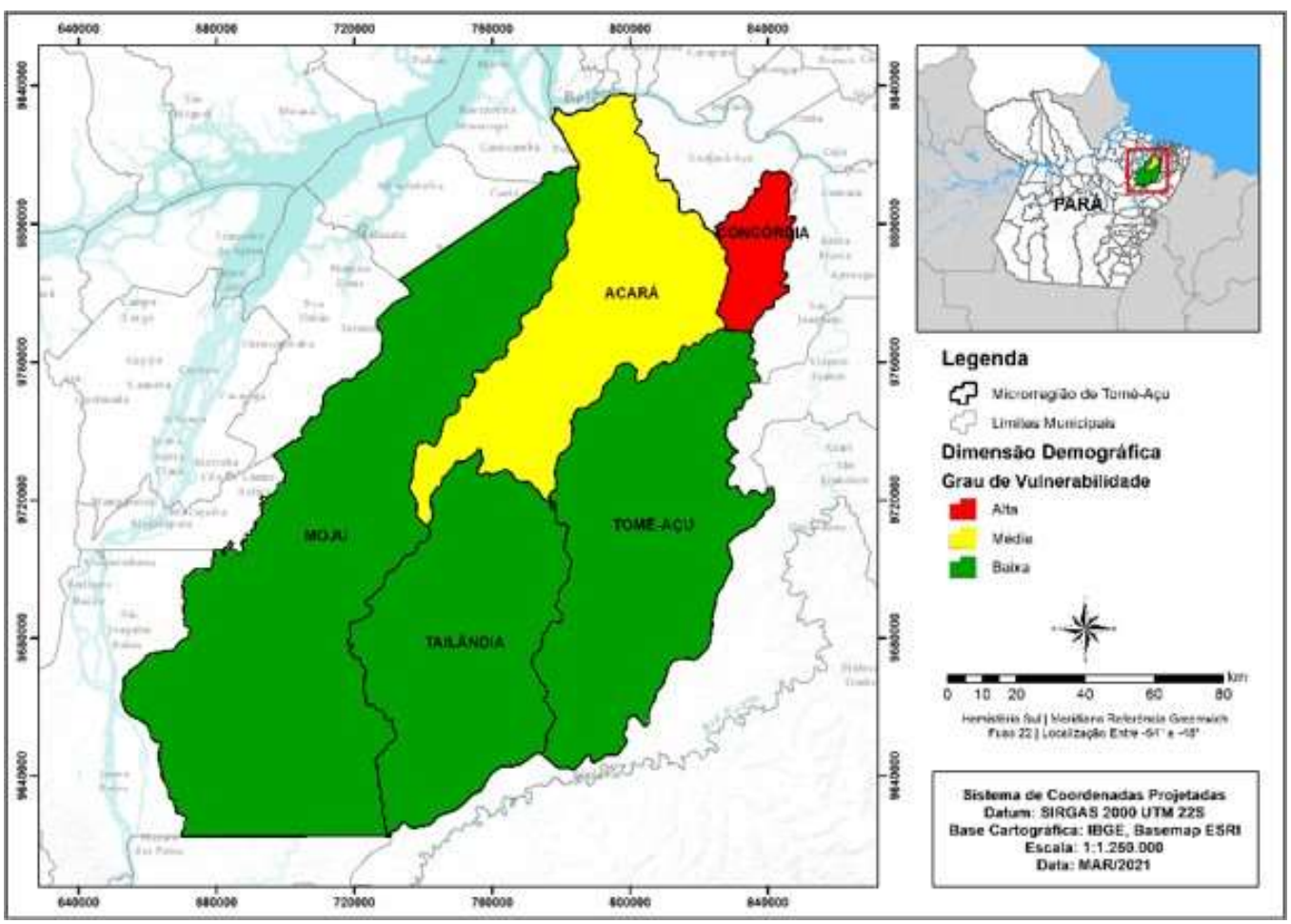

Fonte: Autores. Dados: IBGE (2010).

\subsection{Dimensão social}

Dos cinco municípios da MRTA, quatro tiveram pouca variação nas taxas somadas de crianças e idosos (em torno de 29,9\%), excetuando-se Tailândia, que apresentou uma taxa ligeiramente menor em comparação com os demais (26,9\%). Considerando os valores encontrados para esta variável, considera-se que as pessoas nessas fases da vida não possuem capacidade de resposta adequada frente a um possível desastre, pois são dependentes de outras pessoas por possuírem mobilidade comprometida (Bodstein et al., 2014). Inferindo-se que a maioria delas habita a área rural, possivelmente, estariam sob a classificação de média a alta vulnerabilidade à ameaça de fogo e seus derivados, pelo fator exposição, excetuando-se apenas Tailândia, que possui a maior parte da população habitando áreas urbanas.

Acará apresentou a maior taxa de pessoas com graus de escolaridade baixa e a menor com graus de escolaridade intermediário e elevados, Tailândia apresentou a maior taxa de pessoas com graus de escolaridade alta e a menor com graus de escolaridade baixa, Concórdia do Pará possui a segunda maior taxa de pessoas com graus de escolaridade mais elevados e intermediários e segunda menor em escolaridade baixa. Moju e Tomé-açu apresentaram valores similares acerca da taxa de pessoas em todos os graus de escolaridade, sendo dominante nesses municípios os graus de escolaridade baixos.

O município de Acará está sob a classificação de alta vulnerabilidade social à ameaça de fogo pois este município detém o maior percentual de pessoas com baixa escolaridade e maior taxa (somada) de crianças e idosos ao se inferir que a população tem reduzida criticidade e alguma, ou nenhuma, capacidade de resposta em caso de desastres envolvendo fogo e seus derivados. Tailândia aparece sob a classificação de baixa vulnerabilidade justificada por possuir menor taxa (somada) de crianças e idosos e população que, apesar de possuir em torno de 50\% de pessoas com níveis de escolaridade baixa, também possui o maior número de pessoas (cerca de 10\%) com taxa de escolaridade mais elevada. Os demais municípios possuem, basicamente, as mesmas taxas concernentes a grupos de vulneráveis (crianças e idosos) e escolaridade, o que os submete à classificação de média vulnerabilidade à ameaça de fogo. 
Andrade et al. (2017) afirmam que na mesorregião nordeste paraense, onde se insere a MRTA, a maior parte da população possui baixa escolaridade, entretanto, os grupos de risco abrangendo crianças e idosos não são a maioria. Os autores admitem também que essa mesorregião possui escolas e hospitais que podem oferecer abrigo e assistência médica por ocasião de desastres naturais, elevando a capacidade de suporte da região e explica, em parte, os resultados desse estudo.

Este trabalho, demonstra que no que concerne as variáveis escolaridade e grupos de vulneráveis por faixa etária (crianças e idosos), há necessidade de incentivo em educação formal e não-formal com consequente elevação da criticidade e capacidade de resposta dessa população, bem como políticas públicas mais concretas que assegurem a garantia de direitos desse grupo de vulneráveis, pois, crianças são consideradas vulneráveis porque não conseguem agir e se recuperar sozinhas diante de um desastre (Mitchell et al., 2009), idosos possuem mobilidade comprometida e precisam de cuidados especiais diante das mesmas circunstâncias (Bodstein et al., 2014). Infere-se, assim, que o grau de escolaridade confere às pessoas a capacidade de perceber os riscos a que estão expostos e melhor se preparar para um possível desastre.

\subsection{Análise dos Componentes Principais da MRTA}

A Análise do Componente Principal (ACP) resultou de uma matriz contendo dados demográficos e sociais, onde os dois primeiros eixos foram selecionados porque explicaram juntos $95,98 \%$ da variação total dos dados. O primeiro eixo da PCA explicou 79,58\% da variação total. O segundo eixo explicou 16,40\%, exibindo valores relevantes para densidade demográfica. Os dois primeiros CP resumem de forma efetiva a variância amostral total, podendo ser utilizados para o estudo de conjunto de dados (Gráfico 2).

Gráfico 2 - Análise de Componentes Principais para variáveis sociodemográficas da MRTA.

$($ Dens. $=$ Densidade demográfica, Pop. Rural = População Rural, Esc. $=$ Escolaridade $)$.

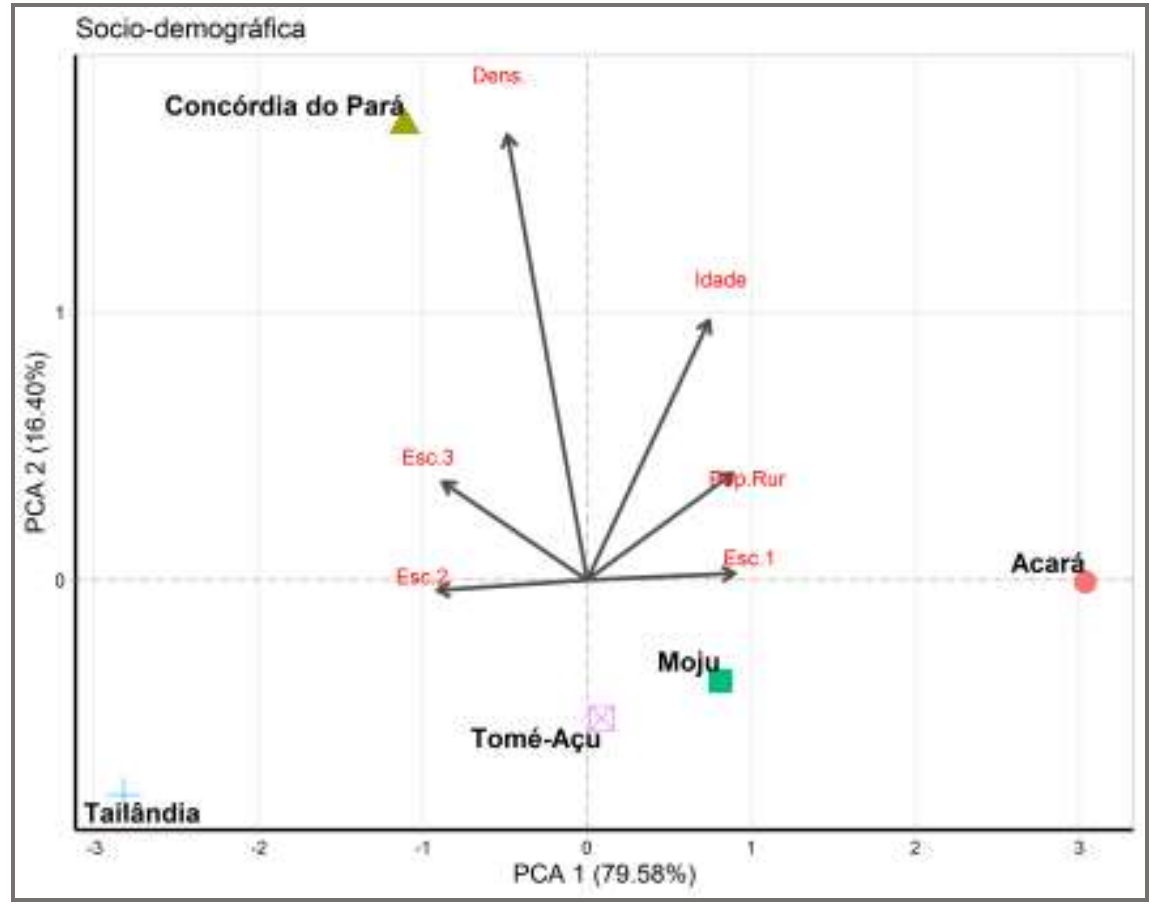

Fonte: Autores. Dados: IBGE (2010).

O município de Acará encontra-se associado às variáveis Escolaridade 1 (Sem instrução a fundamental incompleto), população rural e idade (crianças até 10 anos e pessoas maiores de 60 anos) que juntas lhe conferem a classificação de alta 
vulnerabilidade social e média vulnerabilidade demográfica, Concórdia do Pará sofre maior influência da variável densidade demográfica, faixa etária e influência moderada de Escolaridade 3 (Nível médio completo a superior incompleto), portanto, classifica-se sob média vulnerabilidade social e alta vulnerabilidade demográfica, Moju e Tomé-açu associa-se a Escolaridade 1, Tailândia sofre pouca influência de todas as variáveis, encontrando-se numa zona de baixa vulnerabilidade social e demográfica, Tomé-açu e Moju encontra-se numa zona intermediária associado moderadamente a Escolaridade 2 (nível fundamental completo a médio incompleto) e 1, que os direciona para média vulnerabilidade social à ameaça de fogo.

\subsection{Dimensão ambiental}

\subsubsection{Precipitação pluviométrica}

As médias anuais de precipitação pluviométrica para MRTA variam de $1212 \mathrm{~mm} / \mathrm{m}^{2}$ a $3275 \mathrm{~mm} / \mathrm{m}^{2}$ (Tabela 1). O município que apresentou as menores médias anuais, abaixo de $1500 \mathrm{~mm} / \mathrm{m}^{2}$, foi Moju $\left(1212,05 \mathrm{~mm} / \mathrm{m}^{2}, 1364,6 \mathrm{~mm} / \mathrm{m}^{2}\right.$, 1416,2 mm/ $/ \mathrm{m}^{2}$ ), seguido por Tailândia, quando comparadas às médias dos demais. Entretanto, no ano de 2010, Tomé-açu também apresentou média inferior quando comparada a outros anos e, no período entre 2011 e 2019. Tomé-açu, Acará e Concórdia do Pará, apresentaram durante todo o período estudado grandes volumes de precipitação pluviométrica, atingindo valores médios anuais aproximados de 3000mm $/ \mathrm{m}^{2}$ em 2011, no município de Tomé-açu e, em 2018, em Acará. Os municípios de Tailândia e Moju, apesar de apresentarem grandes volumes de precipitação pluviométrica, demonstraram variações em suas médias anuais.

Tabela 1 - Médias observadas de precipitação pluviométrica na MRTA em dez anos (2010 - 2019).

\begin{tabular}{|c|c|c|c|c|c|}
\hline \multicolumn{6}{|c|}{ PRECIPITAÇÃO PLUVIOMÉTRICA MÉDIA (mm/m²) } \\
\hline Anos & Acará & Concórdia do Pará & Moju & Tailândia & Tomé-açu \\
\hline 2010 & 2545,60 & 2038,44 & 1416,20 & 1965,30 & 1851,85 \\
\hline 2011 & 2955,30 & 2609,82 & 1804,55 & 2766,90 & 3275,05 \\
\hline 2012 & 2331,45 & 2336,48 & 1212,05 & 1891,70 & 2467,05 \\
\hline 2013 & 2603,15 & 2514,10 & 1520,70 & 2384,10 & 2570,40 \\
\hline 2014 & 2901,95 & 2879,22 & 2190,45 & 2048,90 & 2139,65 \\
\hline 2015 & 2877,55 & 2203,79 & 1794,05 & 1932,10 & 2020,30 \\
\hline 2016 & 2525,75 & 2294,37 & 1364,60 & 1874,20 & 2169,40 \\
\hline 2017 & 2741,60 & 2595,47 & 2415,65 & 2478,60 & 2502,70 \\
\hline 2018 & 3204,50 & 2600,66 & 2356,00 & 2826,90 & 2651,10 \\
\hline 2019 & 2861,75 & 2967,56 & 1821,75 & 2279,10 & 2645,00 \\
\hline Média & 2754,86 & 2503,99 & 1789,60 & 2244,78 & 2429,25 \\
\hline
\end{tabular}

Fonte: ANA (2020); GPCC (2020).

\subsubsection{Focos de calor na MRTA}

O total de focos de calor na MRTA entre 2010 e 2019 foi de 20571 e o município que liderou o ranking foi Moju, com 8001 (38,89\%), seguido por Acará, com 6387 (31,04\%), Tomé-açu, com 2695 (13,10\%), Tailândia, com 2233 (10,86\%) e Concórdia do Pará, com 1255 (6,10\%).

Em 2010, Acará, Moju, Tailândia e Tomé-açu apresentavam 869, 965, 313 e 389 focos, respectivamente, porém sofreram redução, em média, de $30 \%$ no ano seguinte. Essa redução possivelmente foi devido ao evento climático conhecido como La Nina, que eleva o volume de chuvas na região amazônica e contribui para a diminuição de número de focos de calor. 
Este evento climático começou a se desenvolver em meados de agosto de 2010, após o término do El Nino, e se estendeu até abril de 2011 (CPC, 2020).

Em Concórdia do Pará, o número de focos de calor aumentou em 33 \% entre 2010 e 2011, passando de 112 para 149 focos, que ainda pode ser justificado pelo evento climático El Niño de intensidade moderada, que reduz a taxa de precipitação pluviométrica e umidade, elevando, consequentemente, o número de focos de calor ou esse aumento justifica-se pela intensa pressão que empresas dendeicultoras fizeram neste período (Santana, 2010).

Observou-se nos municípios de Acará e Moju, entre 2014 e 2016, aumento considerável do número de focos de calor, embora não se tenha observado na MRTA, redução considerável no regime de chuvas, o que pode ser explicado por atividades tradicionais envolvendo limpezas de propriedades pra diversos fins.

Concórdia do Pará, Tailândia e Tomé-açu mantiveram seus números de focos de calor estáveis até 2015, decrescendo em 2016. Por outro lado, todos os municípios sofreram elevação abrupta em 2017, e, no ano seguinte, brusca redução de 53,56\%, 42,04\%, 43,8\%, 47,03\% e 50,74\% para os municípios de Moju, Acará, Tomé-açu, Tailândia e Concórdia do Pará, respectivamente. Tailândia, após a operação conhecida como "Arco de Fogo", em 2008, mostrou significativa queda no número de focos de calor e, em 2013, manifestava o menor índice de queimadas após a intervenção do Estado, entretanto, houve crescimento nesses números observados até 2014 (Figueiredo et al., 2015), mantendo-se estáveis até 2015.

Em 2018, nota-se um decréscimo no número de focos de calor, que pode ter ocorrido em função de investimentos do governo federal em planejamento e monitoramento ambiental. Em 2019, Moju e Tailândia mostraram sensível aumento no número de focos de calor, o que pode ter sido provocado por redução de volume de chuva, associados a outros elementos climáticos e motivações políticas (incentivo ao desmatamento por parte do governo, desqualificação de órgãos púbicos responsáveis pelo monitoramento de queimadas).

Ressalta-se que os efeitos dos eventos climáticos conhecidos como El Nino e La Nina podem ser atenuados por outro evento climático/ atmosférico que ocorre no oceano Atlântico Tropical, o Dipolo do Atlântico, influenciando a posição da Zona de Convergência Intertropical (ZCIT) e esta, no regime de precipitação pluviométrica (Reboita \& Santos, 2015), o que pode justificar anos de ocorrência de El Niño, com presença abundante de chuvas na MRTA.

Ainda que a MRTA apresente grande abundância de precipitação pluviométrica, há períodos de estiagem e falta de consciência humana suscitando vários focos de calor, mostrado nos mapas de densidade de calor (Figura 5) indicando a dispersão desses focos na MRTA, não se observando um padrão, variando ano a ano e de acordo com os locais de incidência. Em 2010, 2011, 2013, 2016 e 2019 nota-se em toda a área, maior concentração de focos de calor representando todas as classes de vulnerabilidade (muito baixa, baixa, média, alta e muito alta), em 2012, 2014, 2015 e 2017 houve maior intervalo de distribuição com menor presença de densidades de focos de calor sobre a região, embora ainda, com presença de todas as classes.

Percebeu-se atipicidade relacionada ao ano de 2018, em que a densidade de classe muito baixa dominaria $100 \%$ da MRTA, se não fosse por duas pequenas "manchas" representando as classes baixa e muito alta, ocorrendo sobre o limite municipal Tailândia/ Moju e em Tomé-açu, respectivamente. A ausência de maior adensamento de focos de calor em 2018 pode ter sido causada por um superávit pluviométrico nesse ano, segundo Secretaria de Estado de Meio Ambiente e Sustentabilidade (SEMAS).

Os municípios que exibem densidades de classificação de vulnerabilidade média a muito alta são Acará, Tailândia, Moju e Tomé-açu. Somente em 2018 Acará e Moju não se inserem nesta situação. Em Concórdia do Pará, nos anos de 2011, 2013, 2016 e 2019, observou-se densidades de classes média a alta, período representando maior ameaça de fogo neste município, em função dessas densidades detectadas. 
Figura 5 - Mapas da MRTA com densidades de focos de calor durante 2010 a 2019.

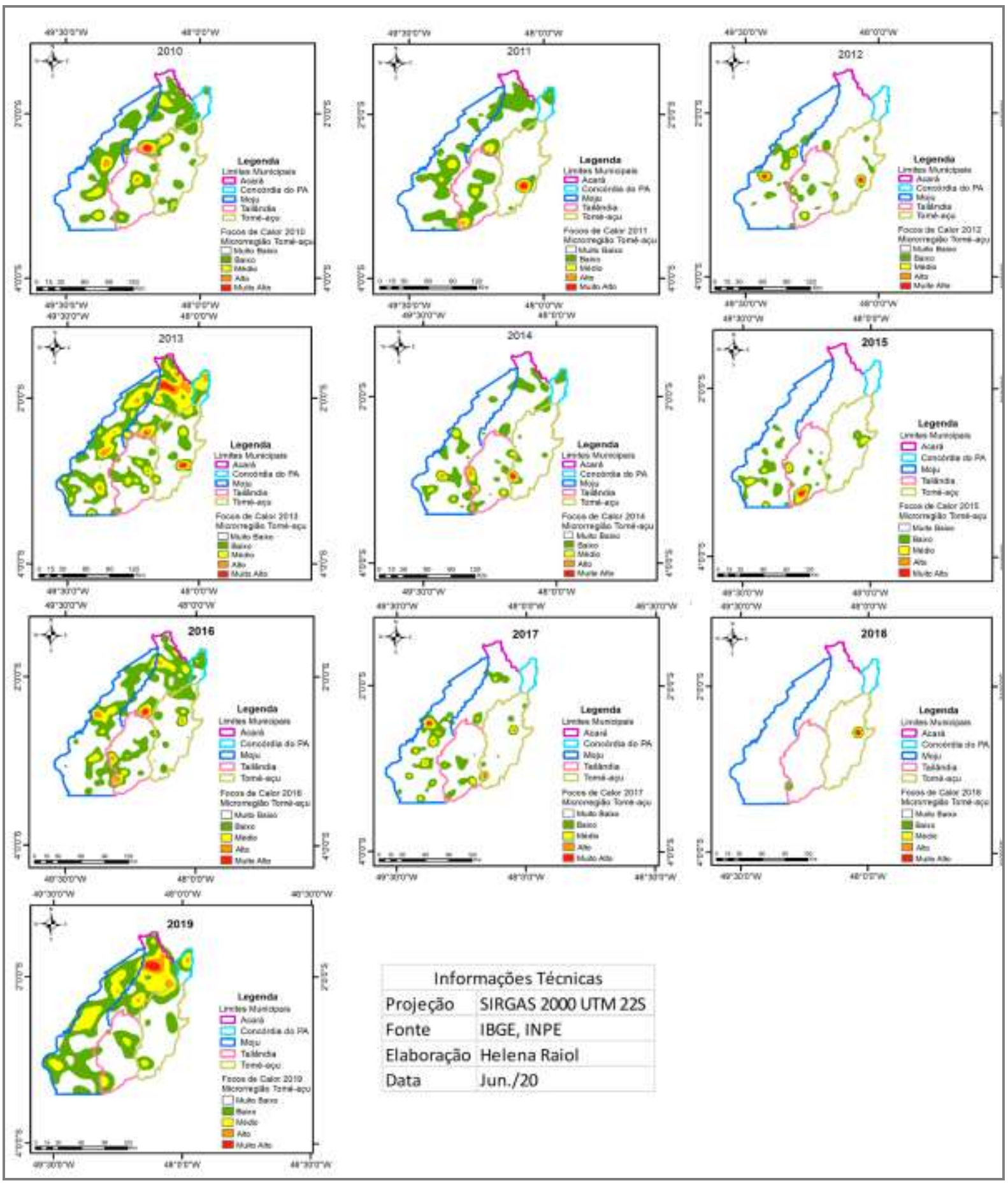

Fonte: Autores. Dados: BDQueimadas, INPE.

\subsubsection{Uso do Solo}

$\mathrm{Na}$ área estudada, o uso do solo está representado pelas seguintes classes: florestas (primárias, secundárias e em regeneração), pastagens e área agricultável. Assim, a pesquisa realizada nos municípios demonstrou a alteração sofrida em seu s parâmetros naturais ao longo de dez anos resultando na transformação da vegetação primária, após intervenção antrópica, em fragmentos florestais, áreas de agricultura, pastagens, solo exposto e provocando alterações na hidrografia local.

Comparando o cenário entre 2010 e 2019 (Figuras 6A e 6B), percebe-se que as áreas urbanas da MRTA sofreram acréscimo pouco perceptível, sugerindo a existência da força de trabalho concentrada nas zonas rurais. As áreas de florestas 
primária e secundária, representadas também por plantações de dendê e de outras culturas, tiveram acréscimo nos municípios de Acará, Concórdia do Pará e Moju, possivelmente devido aos plantios de dendê e outras lavouras, porém, decresceram em Tailândia e Tomé-açu, supostamente por ocasião de presença marcante de solo exposto identificados nesses municípios. Identificou-se áreas acrescidas de pastagens em Concórdia do Pará, podendo ser resultado da exclusão dos dados de áreas não observadas e de solo exposto no cálculo final usados neste estudo. Em Moju, o aumento das áreas de floresta está supostamente relacionado a atividade de bovinocultura (Lima et al., 2015), manteve-se inalterada em Tailândia, reduziu em Acará e Tomé-açu, talvez, porque essas áreas tenham sido substituídas por solo exposto. A área relacionada a hidrografia sofreu redução em todos os municípios, sendo mais acentuada nos municípios de Tailândia $(0,17 \%)$, Acará $(0,17 \%)$ e Moju $(0,12 \%)$, provavelmente, ocasionada por severa intervenção antrópica. O processo de ocupação associado ao desmatamento seletivo, atividade agrícola e a pecuária altera as áreas de florestas, prejudicando matas ciliares, nascentes e interferindo na qualidade da água (Miranda et al., 2016), acarretando o assoreamento dos rios.

Figura 6- Paisagem do uso do Solo da MRTA em 2010 (A) e em 2019 (B).

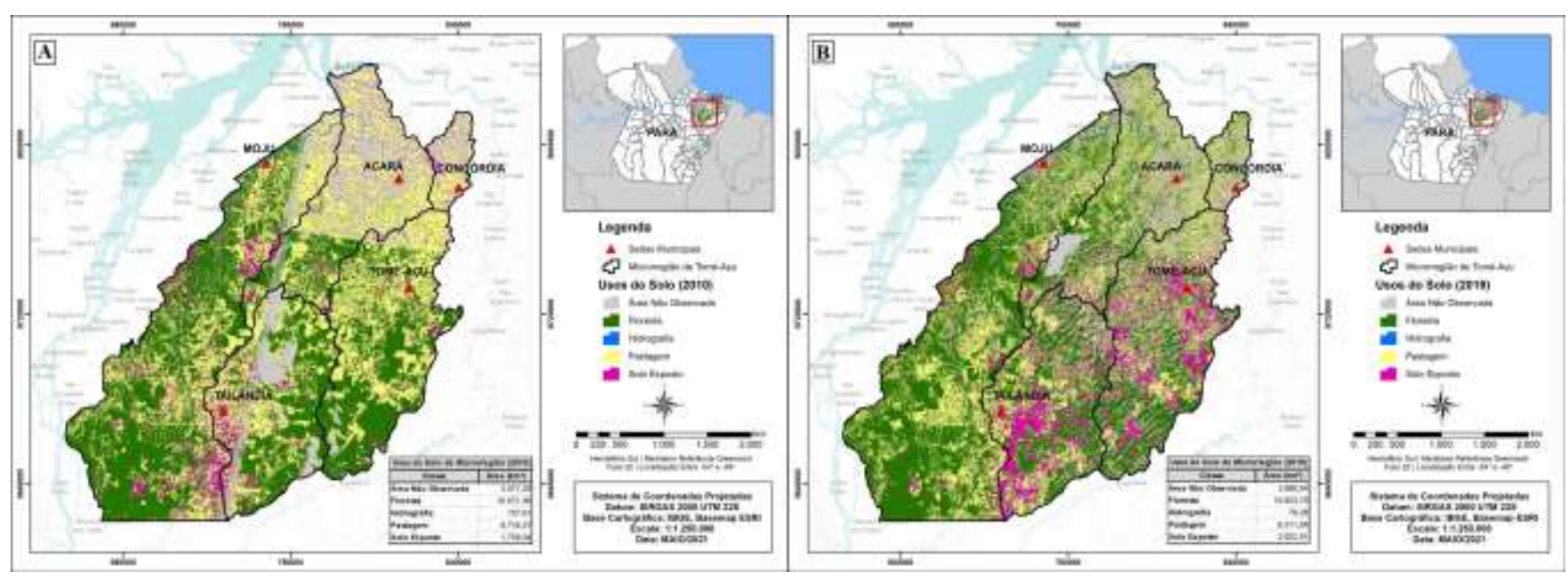

Fonte: Autores. Dados: IBGE (2010); INPE (2014).

\subsection{Mapa de Vulnerabilidade socioambiental da MRTA}

O mapa de vulnerabilidade socioambiental da MRTA à ameaça de fogo classifica como alta vulnerabilidade Concórdia do Pará, como média vulnerabilidade Acará e como baixa vulnerabilidade Moju, Tailândia e Tome-açu (Figura 7).

O município de Concórdia do Pará apresentava 23,63\% de floresta, cerca de 35\% de pastagem, média anual de 125,5 focos de calor e a menor rede hidrográfica da MRTA $(0,02 \%)$, menor área territorial da MRTA e precipitação pluviométrica média anual de $2504 \mathrm{~mm} / \mathrm{m}^{2}$. A reunião dessas características ambientais com as sociodemográficas desse município convergem para a construção do indicador de alta vulnerabilidade socioambiental à ameaça de fogo justificada pela presença da população com níveis mais baixos de escolaridade, deduzindo-se que há maior exposição da população ao perigo do fogo, uma vez que há alta vulnerabilidade ambiental e social.

Acará possui 34,16\% de floresta e 28,75\% de pastagens, a maior rede hidrográfica da MRTA (0,69\%), média anual de 638,7 focos de calor e volume médio anual de chuvas em torno de $2.750 \mathrm{~mm} / \mathrm{m}^{2}$, e todos esses fatores ambientais associados ao sociodemográficos direcionam este município para a construção do indicador de média vulnerabilidade socioambiental à ameaça de fogo. Pois, ainda que algumas variáveis ambientais direcionem Acará para baixa vulnerabilidade ambiental, as variáveis sociais elevam essa condição, pois se constitui da maioria das pessoas que, teoricamente, não possuem criticidade nem capacidade de resposta diante do perigo ou ameaça. 
Moju detinha áreas de floresta (cerca de 60\%), pastagem (cerca de 29\%) e a segunda maior área hidrológica da MRTA (0,5\%), cujo principal representante é o rio Moju, apresentou a média anual de 800,1 focos de calor, volume de chuvas variando de 1.220 a $2.500 \mathrm{~mm} / \mathrm{m}^{2}$ no período analisado, possui a menor densidade demográfica da MRTA $\left(9,03 \mathrm{hab} . / \mathrm{km}{ }^{2}\right), \mathrm{com}$ população rural maior que a urbana, distribuída no maior município da MRTA, cerca de 30\% da população é composta por crianças e idosos, é o segundo município da região, cuja população possui os menores níveis de escolaridade (57,44\%), conferindo-lhe baixa capacidade de resposta e, embora algumas variáveis sociais contribuam para elevar a classificação do indicador de vulnerabilidade socioambiental, a junção das variáveis ambientais e sociodemográficas colaboram para a construção do indicador de baixa vulnerabilidade socioambiental à ameaça de fogo.

Tailândia possuía florestas (40,97\%), pastagens (26,14\%), média anual de focos de calor: 223,3 e de precipitação pluviométrica em torno de $2200 \mathrm{~mm} / \mathrm{m}^{2}, 0,04 \%$ de área hidrográfica que, aliados aos fatores sociodemográficos o classificam como baixa para o indicador de vulnerabilidade socioambiental à ameaça de fogo, embora as condições ambientais possuam variáveis desfavoráveis, infere-se que a condição social da população que, neste caso, apresenta maior criticidade e capacidade de resposta, colabora para a construção dessa classificação.

Tomé-açu apresentava cerca de 38\% de áreas de floresta e de $23 \%$ de pastagem, pequena área referente a hidrologia local $(0,04 \%)$, média 269,5 focos de calor por ano, volume de chuvas variando de $1.851,85$ a $3.275,05 \mathrm{~mm} / \mathrm{m}^{2}$ no período do estudo. Esses fatores ambientais associados aos sociodemográficos de Tomé-açu sugerem um indicador de baixa vulnerabilidade socioambiental à ameaça de fogo. Ainda que essa população demonstre criticidade e capacidade de resposta comprometidas devido o baixo grau de escolaridade, suas condições ambientais favorecem a classificação obtida, pois, segundo o relatório da Fapespa (2016), ao longo das margens dos rios e seus afluentes existem grandes áreas de florestas ombrófilas.

Figura 7: Mapa de vulnerabilidade socioambiental da MRTA.

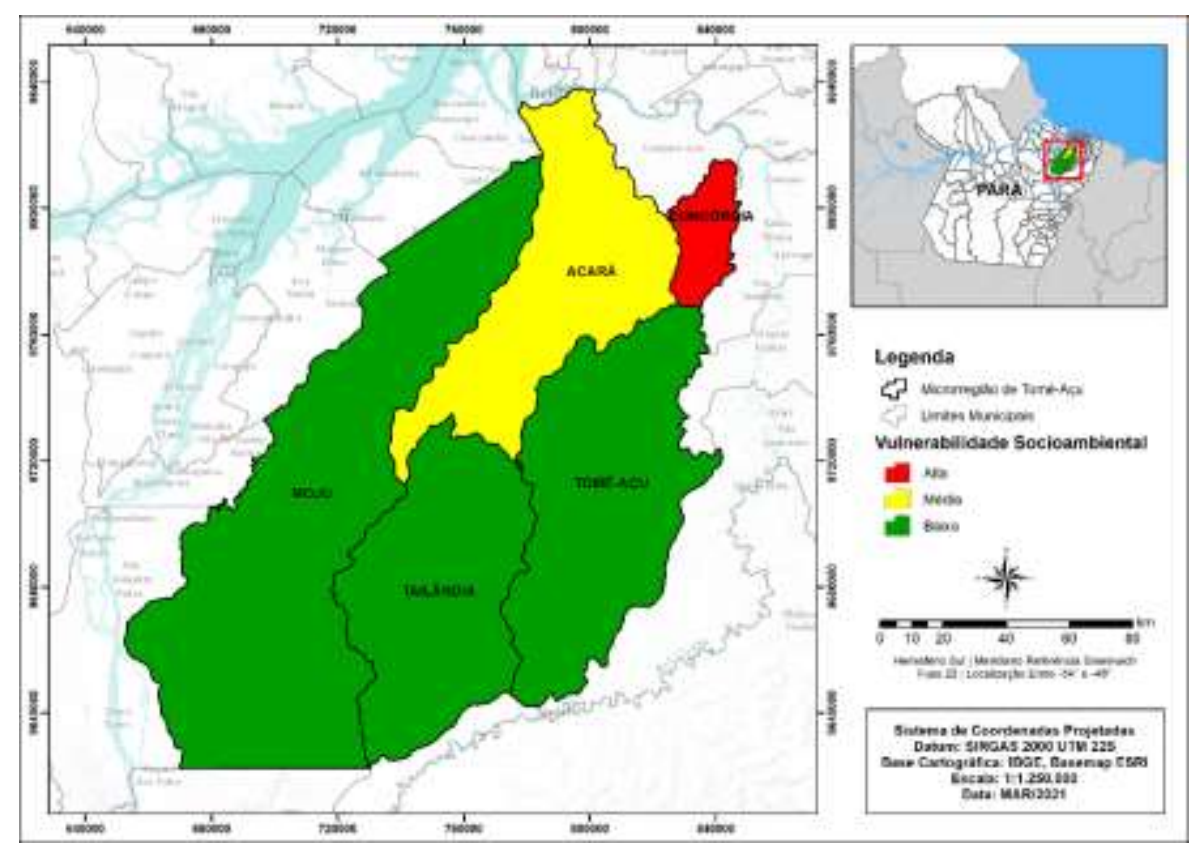

Fonte: Autores. Dados: IBGE (2010).

\section{Conclusão}

A Microrregião de Tomé-açu (MRTA) revelou várias suscetibilidades ambientais e sociodemográficas, entretanto, foi a dimensão social que mais contribuiu para a classificação das vulnerabilidades dos municípios, agravado pela variável grau de 
escolaridade. A população dessa região conseguiu adaptar-se às transformações, sofridas por ocasião das mudanças em suas atividades laborais, no entanto, ainda se faz necessário maior incentivo à elevação de escolaridade tanto em espaços formais como em não-formais para que se obtenha capacidade de resposta e criticidade para enfrentamento a possíveis desastres construindo, assim, comunidades resilientes. Acerca das condições ambientais, faz-se necessário que as leis de proteção aos recursos naturais sejam cumpridas ou fiscalizadas com rigor e que se possa oferecer à população rural melhores condições de vida para que seja, no mínimo, reduzido o fator exposição.

O momento atual requer mudança de comportamento a fim de que a Terra ofereça condições de vida mais sustentáveis e seguras, portanto, faz-se necessário que, dentre muitas pesquisas científicas, a temática vulnerabilidade socioambiental envolvendo desastres naturais seja mais abordada, para que se construa uma sólida gestão de risco de desastre no sentido de prevenir a ocorrência do próprio desastre, principalmente, no tocante a queimadas e incêndios florestais na Amazônia.

\section{Referências}

AFP - Agence France Presse. (2018, julho 26). Relembre os incêndios florestais mais mortais do século em todo o mundo. $O$ Globo. https://oglobo.globo.com/mundo/relembre-os-incendios-florestais-mais-mortais-do-seculo-em-todo-mundo-22919149.

ANA - Agência Nacional de Águas e Saneamento Básico (2020). Mapa. https://www.snirh.gov.br/hidroweb/mapa

Alvares, C. A., Stape, J. L., Sentelhas, P. C., Gonçalves, J. D. M. \& Sparovek, G. (2013). Köppen's climate classification map for Brazil. Meteorologische Zeitschrift. 22 (6) $711-728$.

Anderson, L. O., Marchezini, V, Morello, T. F. \& Cunningham, C. A. (2019). Modelo conceitual de sistema de alerta e de gestão de riscos e desastres associados a incêndios florestais e desafios para políticas públicas no Brasil. Territorium, 26 (1), 43-61.doi: 10.14195/1647-7723_26-1_4

Anderson, L. \& Marchezini, V. (2020). Mudanças na exposição da população à fumaça gerada por incêndios florestais na Amazônia: o que dizem os dados sobre desastres e qualidade do ar? Saúde Debate, 44 (esp. 2), 284-302. doi: 10.1590/0103-11042020E220

Andrade, M. M. N. de, Andrade, A. de S. \& Bezerra, P. E. S. (2017). Índice de vulnerabilidade aos desastres naturais no estado do Pará (Brasil). Revista DELOS Desarrollo Local Sostenible, 10 (30), 1-16. https://www.eumed.net/rev/delos/30/desastres-naturais-para.html

Araújo, M. L. de \& Becker, B. K. (2011). Amazônia: geopolítica na virada do III milênio. Ateliê Geográfico, 5(1), 269-275. https://www.revistas.ufg.br/atelie/article/view/13835

Bacani, V. M (2016). Geoprocessing applied to risk assessment of forest fires in the municipality of Bodoquena, Revista Árvore, 40 (6), 1003-1011. https://doi.org/10.1590/0100-67622016000600005

Bodstein, A., Lima, V. V. A. de \& Barros, A. M. A. de (2014). A vulnerabilidade do idoso em situações de desastre: necessidade de uma política de resiliência eficaz. Ambiente \& Sociedade, 17(2), 157-174. https://www.scielo.br/j/asoc/a/mVBdgwpNz5YymN4tTQZHGXR/?format=pdf\&lang=pt

Cardoso, F. H. \& Muller, G. (2008). Amazônia: a expansão do capitalismo. Rio de Janeiro: Centro Edelstein de Pesquisas Sociais. https://doi.org/10.7476/9788599662731

Carvalho, A. C. A. de. (2016). Dendeicultura em Tomé-açu (PA): metamorfoses no trabalho e no espaço na vila Forquilha. Revista Caribeña de Ciencias Sociales. https://www.eumed.net/rev/caribe/2016/12/dendeicultura.html

Castro, H. A., Gonçalves, K. S. \& Hacon, S. S. (2009). Tendência da mortalidade por doenças respiratórias em idosos e as queimadas no estado de Rondônia/Brasil - período entre 1998 e 2005. Ciência \& Saúde Coletiva, 14 (6), 2083-2090.

CPC - Climate Prediction Center. (2020). Cold \& $\quad$ season. https://origin.cpc.ncep.noaa.gov/products/analysis_monitoring/ensostuff/ONI_v5.php

Cochrane, M. A. (2000). O grande incêndio de Roraima. Ciência Hoje, 27 (157), 26-43.

Cordeiro, I. M. C. C., Arbage, M. J. C. \& Schwartz, G. (2017). Nordeste do Pará: configuração atual e aspectos identitários. Em I. M. C. C. Cordeiro, L. G. T. Rangel-Vasconcelos, G. Schwartz \& F. de A. Oliveira, (orgs.). Nordeste paraense: panorama geral e uso sustentável das florestas secundárias (pp. 19-58). Brasil, Belém: EDUFRA.

Costa, M. R. G. F., Cândido, M. J. D., Carneiro, M. S. de S., Morais Neto, L. B. de, Magalhães, J. A. \& Costa, N. L. (2011). Uso do fogo em Pastagens Naturais. PUBVET, 5 (9), 1050-1057.

DNIT - Departamento Nacional de Infraestrutura de Transportes. (2019). Mapas multimodais. http://servicos.dnit.gov.br/dnitcloud/index.php/s/8gXNYH53mabZwaf\#pdfviewer 
Figueiredo, B. L., Costa J. A. da \& Tavares L. C. (2015). Avaliação temporal e espacial das ocorrências de focos de calor em relação as estradas no município de Tailândia - Pará (Resumo). In: Simpósio Brasileiro de Sensoriamento Remoto [Eds.]. Anais, XVII Simpósio Brasileiro de Sensoriamento Remoto (p.68036809). João Pessoa, PB: INPE.

Fonseca-Morello, T., Ramos, R., Steil, L., Parry, L., Barlow, J., Markusson, N. \& Ferreira, A. (2017). Queimadas e incêndios florestais na Amazônia brasileira: por que as políticas públicas têm efeito limitado? Ambiente \& Sociedade, 20 (4), 19-40. doi.org/10.1590/1809-4422asoc0232r1v2042017

Freitas, C. M., Carvalho, M. L. de, Ximenes, E. F., Arraes, E. F. \& Gomes, J. O. (2012). Vulnerabilidade socioambiental, redução de riscos de desastres e construção da resiliência: lições do terremoto no Haiti e das chuvas fortes na Região Serrana, Brasil. Ciência \& Saúde Coletiva, 17 (6), $1577-1586$. https://doi.org/10.1590/S1413-81232012000600021

FAPESPA - Fundação Amazônia de Amparo a Estudos e Pesquisas. (2016). Diretoria de Estatística e de Tecnologia e Gestão da Informação. Estatísticas municipais paraenses: Tomé-Açu. Belém, Fapespa. Recuperado de https://drive.google.com/file/d/1433oZ9c35UDYOmNw3_FyAe_pyZQZURF1/view

Gamba, C. \& Ribeiro, W.C. (2012). Indicador e avaliação da vulnerabilidade socioambiental no município de São Paulo. GEOUSP - Espaço e Tempo, 16 (1), 19-31. Doi: https://doi.org/10.11606/issn.2179-0892.geousp.2012.74266

Gonçalves, K. dos S., Siqueira, A. S. P., Castro, H. A. \& Hacon, S. de S. (2014). Indicador de vulnerabilidade socioambiental na Amazônia Ocidental. O caso do município de Porto Velho, Rondônia, Brasil. Ciência \& Saúde Coletiva, 19 (9), 3809-3818. https://doi.org/10.1590/1413-81232014199.14272013

Hirst, K. (2020, November 19). The Discovery of Fire. Retrieved from https://www.thoughtco.com/the-discovery-of-fire-169517

IBGE - Instituto Brasileiro de Geografia e Estatística. (2019). Geociências. https://www.ibge.gov.br/geociencias/organizacao-do-territorio/malhasterritoriais/15774-malhas.html?edicao=27733\&t=downloads

IBGE - Instituto Brasileiro de Geografia e Estatística. (2010). Censo Demográfico. https://cidades.ibge.gov.br/brasil/pa/panorama

INCRA - Instituto Nacional de Colonização e Reforma Agrária. (2019). Divisão de obtenção de terras e implantação de projetos de assentamento - SR (01) /T. (Publicação SEI/INCRA - 3647007 - RAMT - Relatório de Análise de Mercado de Terras). Superintendência Regional do Pará.

INPE - Instituto Nacional de Pesquisas Espaciais (2014, 02 abril, 2018). Projeto Terraclass. http://www.inpe.br/cra/projetos_pesquisas/terraclass2014.php

INPE - Instituto Nacional de Pesquisas Espaciais (2020). Banco de Queimadas. https://queimadas.dgi.inpe.br/queimadas/bdqueimadas\#

Lameira, W.J. de M., Vieira, I.C.G. \& Toledo, P.M. de (2015). Análise da expansão do cultivo da palma de óleo no Nordeste do Pará. Novos Cadernos NAEA, 18 (2), 185-197. Doi: http://dx.doi.org/10.5801/ncn.v18i2.1990

Lima, C., Silveira, A. \& França, I. (2015). Dimensão produtiva da agricultura familiar: estudo de caso no projeto de assentamento Vale do Moju-PA. Enciclopédia Biosfera, 11(21), 777-793. Recuperado de https://conhecer.org.br/ojs/index.php/biosfera/article/view/1798

Marinho, A. A. R. et al. (2021). Temporal record and spatial distribution of fire foci em State of Minas Gerais, Brazil. Journal of Environmental Management, 280, 111707. doi.org/10.1016/j.jenvman.2020.111707

Morato, R. G. (2008). Análise espacial e desigualdade ambiental no município de São Paulo (Tese de Doutorado), Programa de Pós-Graduação de Geografia Humana, Faculdade de Filosofia, Letras e Ciências Humanas, Universidade. de São Paulo, SãoPaulo. Doi: 10.11606/T.8.2008.tde-25112009-112210

Miranda, V. T., Santos, M. L. S., Pereira, J. A. R. \& Mesquita, K. F. C. (2016). Índices de qualidade da água da Ilha de Mosqueiro-PA. Revista DAE, 64, 7481. DOI: $10.4322 /$ dae. 2015.005

Mitchell, T., Tanner, T. \& Haynes, K. (2009). Children as agents for disaster risk reduction: lessons from El Salvador and the Philippine. Eldis. https://www.eldis.org/document/A43151

Musitano, M. (2019). O homem e o fogo. Invivo. http://www.invivo.fiocruz.br/cgi/cgilua.exe/sys/start.htm?infoid=1014\&sid=9.

GPCC - Global Precipitation Climatology Centre). (2020, 27 Feb. 2020). The Climate Data Guide. Retrieved from https://climatedataguide.ucar.edu/climatedata/gpcc-global-precipitation-climatology-centre

Nepstad, D. C., Moreira, A. G. \& Alencar, A. A. (1999). A floresta em chamas: origens, impactos e prevenção de fogo na Amazônia. Programa Piloto para a Proteção das Florestas Tropicais do Brasil, Brasília, Brasil.

Nahum, J. S. \& Malcher, A. T. C. (2012). Dinâmicas territoriais do espaço agrário na Amazônia: a dendeicultura na microrregião de Tomé-Açu (PA). Revista Franco-Brasileira de Geografia -confins, 16 (12). https://doi.org/10.4000/confins. 7947

Pinho, G. F. de. (2015). Relação entre a condição de mobilidade da população e acesso às políticas públicas em Moju e Acará-PA. Dissertação de Mestrado em Ciências Ambientais e Desenvolvimento Sustentável. Belém, Pará, Brasil.

Rebello, F. K. \& Homma, A. K. O (2017). História da colonização do Nordeste Paraense: uma reflexão para o futuro da Amazônia. Belém: EDUFRA.

Reboita, M. S. \& Santos, I. (2015). Influência de alguns padrões de teleconexão na precipitação no norte e nordeste do Brasil. Revista Brasileira de Climatologia, 15, 28-48. DOI: http://dx.doi.org/10.5380/abclima.v15i0.37686

Santana, R. M (2010). Os caminhos da regularização fundiária no município de Concórdia do Pará/PA. Dissertação de Mestrado em Geografia Humana, Faculdade de Filosofia, Letras e Ciências Humanas, Universidade de São Paulo, São Paulo.

Santos, K. S., Silva, D. D. da, \& Guimarães R. J. de P. S. e. (2020). Análise multitemporal de focos de queimadas e variáveis climáticas, no Estado do Pará. Rev. Geogr. Acadêmica, 14 (1), 118-133. 
Research, Society and Development, v. 11, n. 2, e27711225732, 2022

(CC BY 4.0) | ISSN 2525-3409 | DOI: http://dx.doi.org/10.33448/rsd-v11i2.25732

Santos, L. S. dos, Nahum, J. S., Santos, C. B. dos \& Silva Júnior, O. M. (2019). Paisagem rural da microrregião de Tomé-Açu sob a ótica bertrandiana. Revista Brasileira de Geografia Física, 12 (07), 2694-2715.

SEMAS - Secretaria de Estado de Meio Ambiente e Sustentabilidade. (2010). Instrução Normativa N.51, de 08 de setembro de 2010. Dispõe sobre a Autorização de Queima Controlada no âmbito do Estado do Pará e dá outras providencias. Belém - Pará. https://www.semas.pa.gov.br/2010/09/08/10976/.

Silverman, B. W. (1986). Density estimation for statistics and data analysis. London: Chapman and Hall. Monographs on statistics and applied probability, School of Mathematics, University of Bath, UK. https://ned.ipac.caltech.edu/level5/March02/Silverman/paper.pdf

Sousa, A. M. L. de, Rocha, E. J. P. da, Vitorino, M. J., Souza, P. J. O. P. de \& Botelho, M. N. (2015). Variabilidade espaço-temporal da precipitação na Amazônia durante eventos ENOS. Revista Brasileira de Geografia Física, 8 (1), 13-24. https://doi.org/10.26848/rbgf.v8.1.p013-024

Souza, M. B. de, Dias, G. F. de M., Miranda, S. B. de A. de, Nascimento, R. E. N. do, Gama, L. H. O. M. \& Paiva, P. F. P. R. (2021). Dinâmica de uso e cobertura do solo associada a focos de calor no município de Poconé-MT. Research, Society and Development, 10 (3), e0710312930. DOI: https://doi.org/10.33448/rsd-v10i3.12930

Wigtil, G., Hammer, R. B., Kline, J. D., Mockrin, M. H., Stewart, S. I., Roper, D. \& Radeloff, V. C. (2016). Places where wildfire potential ans social vulnerability coincide in the coterminous United States. International Journal of Wildland Fire, 25, p. 896-908. https://doi.org/10.1071/WF15109

Xiong, Q. et al. (2020). Fire from policy, human interventions, or biophysical factors? Temporal - spatial patterns of forest fire in southwestern China. Forest Ecology and Management, 474, 118381. https://doi.org/10.1016/j.foreco.2020.118381 